\title{
Detection of Human Anti-Trypanosoma cruzi Antibody with Recombinant Fragmented Ribosomal P Protein
}

\author{
Yeong Hoon Kim¹, Zhaoshou Yang², Jihoo Lee ${ }^{3}$, Hye-Jin Ahn², Chom-Kyu Chong ${ }^{3}$, Wagner Maricondi", \\ Ronaldo F. Dias ${ }^{4}$, Ho-Woo Nam ${ }^{2, *}$
}

\begin{abstract}
${ }^{1}$ Department of Ophthalmology, College of Medicine, The Catholic University of Korea, Seoul 06591, Korea; '2Department of Parasitology, College of Medicine, The Catholic University of Korea, Seoul 06591, Korea; ${ }^{3}$ GenBody Inc., Cheonan 31116, Korea; ${ }^{4}$ WAMA Diagnostica, Aldo Germano Clein, 100-CEAT, Sao Carlos, CEP. 13573-470, SP-Brazil
\end{abstract}

\begin{abstract}
Chagas disease is caused by the protozoan parasite Trypanosoma cruzi, and is endemic in many Latin American countries. Diagnosis is based on serologic testing and the WHO recommends two or more serological tests for confirmation. Acidic ribosomal P protein of $T$. cruzi showed strong reactivity against positive sera of patients, and we cloned the protein after fragmenting it to enhance its antigenicity and solubility. Twelve positive sera of Chagas disease patients were reacted with the fragmented ribosomal $\mathrm{P}$ protein using western blot. Detection rate and density for each fragment were determined. Fragments F1R1, F1R2, and F2R1 showed 100\% rate of detection, and average density scoring of 2.00, 1.67, and 2.42 from a maximum of 3.0 , respectively. Therefore, the F2R1 fragment of the ribosomal P protein of $T$. cruzi could be a promising antigen to use in the diagnosis of Chagas disease in endemic regions with high specificity and sensitivity.
\end{abstract}

Key words: Trypanosoma cruzi, Chagas disease, ribosomal P protein, GST-fusion protein, western blot, patients' sera

Chagas disease, also known as American trypanosomiasis, is caused by the protozoan parasite Trypanosoma cruzi [1]. It is found in many Latin American countries and is responsible for significant health and economic burden in the area $[2,3]$. The disease spreads mainly through insect vectors, but can also be transmitted orally, congenitally, or through transfusion or organ transplantation in a lesser extent $[1,4]$. The highest incidences are located in resource-constrained areas and rural settings. The World Health Organization (WHO) estimates about 6 million to 7 million people worldwide, mostly in Latin American countries, are infected [5].

Chagas disease does not produce immediate or easily observed symptoms in individuals, but over time, if untreated, can lead to serious cardiac and digestive complications, resulting in loss of productivity and ultimately death. The initial acute phase lasts for roughly two months post infection and many individuals have either no symptoms or only mild symptoms during this time. In the acute phase parasites can be

\footnotetext{
- Received 15 April 2019, revised 3 July 2019, accepted 15 July 2019.

*Corresponding author (howoo@catholic.ac.kr)

(c) 2019, Korean Society for Parasitology and Tropical Medicine

This is an Open Access article distributed under the terms of the Creative Commons Attribution Non-Commercial License (http://creativecommons.org/licenses/by-nc/4.0) which permits unrestricted non-commercial use, distribution, and reproduction in any medium, provided the original work is properly cited.
}

found circulating in the bloodstream and microscopic identification of parasites is recommended. In the subsequent chronic phase, the parasites sequester primarily in cardiac and digestive tissues, potentially causing gradual and severe damage to the organs. Diagnosis is based on serologic testing in asymptomatic individuals. Currently, the WHO recommends the use of 2 or more serological diagnostic tests for confirmation of the infection [6].

Patients' sera were provided by Dr. Wagner Maricondi of the WAMA Diagnostica (Aldo Germano Clein, Sao Carlos, Brazil), which were collected according to the "Bioethics and Security" protocol, and only unnamed samples assigned with numbers under the regulation of the IRB Committee of WAMA Diagnostica (2 January 2014) were provided. Esmeraldo CL2 strain of T. cruzi was purchased from ATCC (ATCC ${ }^{\circledR}$ 50820, Manassas, Virginia, USA) and maintained in ATCC 1029 LIT media at $25^{\circ} \mathrm{C}$ in 25-T flask with 12-14 days passage. Western blot with patients' sera to the whole extract of T. cruzi revealed that a $37 \mathrm{kDa}$ protein was blotted strongly by the entire sera (data not shown). This $37 \mathrm{kDa}$ protein is known as an acidic ribosomal P protein $[7,8]$ and we fragmented the amino acid sequence prior to cloning to enhance its antigenicity and solubility, as designed in Fig. 1A. DNAs were amplified with multiple sets of primers as F1: 5'-CG GGA TCC GTG CAT GAC GTT 
A

\begin{tabular}{|c|c|c|}
\hline All: 1 & & 323 \\
\hline 34 & & 323 \\
\hline 34 & & 315 \\
\hline 34 & 168 & \\
\hline & 161 & 323 \\
\hline & 161 & 315 \\
\hline
\end{tabular}

$\mathrm{B}$

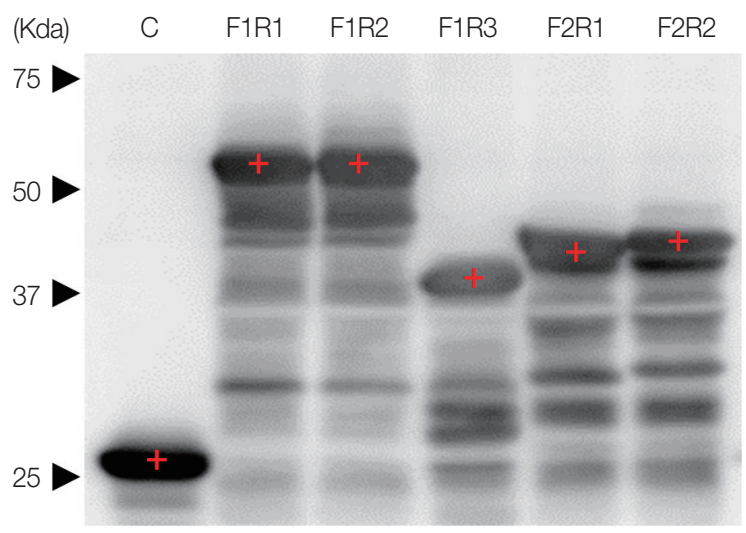

Fig. 1. Production of recombinant $P$ protein fragments. (A) Design of the fragmented acidic ribosomal $P$ protein of $T$. cruzi. (B) Fragments detected with anti-GST antibody by western blot.

Table 1. Reactivity of fragmented ribosomal $P$ protein against positive sera of Chagas disease patients

\begin{tabular}{|c|c|c|c|c|c|}
\hline Pts & F1R1 & F1R2 & F1R3 & F2R1 & F2R2 \\
\hline $\mathrm{N} 1$ & - & - & - & - & - \\
\hline N2 & - & - & - & - & - \\
\hline P1 & +++ & +++ & - & ++ & - \\
\hline P2 & ++ & + & - & ++ & + \\
\hline P3 & ++ & + & - & +++ & - \\
\hline P4 & +++ & ++ & + & +++ & + \\
\hline P5 & ++ & ++ & + & ++ & + \\
\hline P6 & ++ & + & + & +++ & - \\
\hline P7 & + & ++ & - & +++ & ++ \\
\hline P8 & ++ & + & - & +++ & + \\
\hline P9 & +++ & + & + & +++ & + \\
\hline P10 & + & + & - & + & + \\
\hline P12 & ++ & + & + & ++ & - \\
\hline Rate $^{a}(\%)$ & 100 & 100 & 41.7 & 100 & 66.7 \\
\hline Density $^{b}$ & 2 & 1.67 & 0.42 & 2.42 & 0.75 \\
\hline
\end{tabular}

aRate: detection rate of each fragment with positive patients' sera.

bDensity: average density of the bands reacted, scored into 3 degree arbitrarily as $+=1,++=2$, and $+++=3$.

CGT CGC GA-3', F2: 5'-CCG GGA TCC GTG AGT GAC AAG AAG GTA CTG AGC-3', R1: 5'-CCG CTC GAG TTA GAA CAG CGC CCC CAT-3', R2: 5'-CCG CTC GAG AAA GTC GTC GTC ATC ATC CTC CTC T-3' and R3: 5'-CCG CTC GAG GCT CAG TAC CTT CTT GTC ACT CAC-3' to insert into pGEX4T-1 plasmid, and then expressed as GST fusion proteins detected with HRP-conjugated anti-human IgG antibody (Sigma Aldrich, St. Louis, Missouri, USA) as shown in Fig. 1B. Twelve positive sera of Chagas disease patients were reacted with the fragmented ribosomal P protein (Table 1). Rate was determined as the detection rate for each fragment against positive patients' sera. Density of the bands for each fragment against sera were measured as,+++ , and +++ arbitrarily, and scored into 1, 2, and 3.
The averages were calculated and used as the final density. Fragments F1R1, F1R2, and F2R1 showed 100\% rate of detection, and average density scoring of 2.00, 1.67, and 2.42 from a maximum of 3.0, respectively.

Ribosomal P proteins form a complex of proteins in the large subunit of the ribosome that is called the stalk [9]. These proteins act as a molecular switch in the ribosome related to the binding and release of elongation factors and GTP hydrolysis [10].

The C-terminal half of the ribosomal P protein of T. cruzi produce the autoantibodies responsible for Chagas disease. So, this high reactivity of the fragment F2R1 could be used for detecting positive Chagas disease patients. It might be a useful 
diagnostic antigen in immunoaffinity methods such as western blot, ELISA, and even rapid diagnostic test. Therefore, it would serve as a method of choice for point-of-care diagnosis and large-scale surveys in regard to T. cruzi infection among people under clinical or field conditions in endemic areas worldwide.

\section{CONFLICT OF INTEREST}

The authors declare no conflict of interest related to this study.

\section{REFERENCES}

1. Rassi A Jr, Rassi A, Marin-Neto JA. Chagas disease. Lancet 2010; 375: 1388-1402.

2. Hotez PJ, Bottazzi ME, Franco-Paredes C, Ault SK, Periago MR. The neglected tropical diseases of Latin America and the Caribbean: a review of disease burden and distribution and a roadmap for control and elimination. PLoS Negl Trop Dis 2008; 2: e300.

3. Mathers CD, Ezzati M, Lopez AD. Measuring the burden of neglected tropical diseases: the global burden of disease framework. PLoS Negl Trop Dis 2007; 1: e114.

4. Prata A. Clinical and epidemiological aspects of Chagas disease.
Lancet Infect Dis 2001; 1: 92-100.

5. World Health Organization. Chagas disease (American trypanosomiasis) [Internet]; [cited 2019 Mar 20]. Available from: https:// www.who.int/news-room/fact-sheets/detail/chagas-disease(american-trypanosomiasis).

6. World Health Organization. Second WHO consultation on the development of a WHO reference panel for the control of Chagas diagnostic tests [Internet]; [cited 2019 Mar 20]. Available from: https://www.who.int/bloodproducts/ref_materials/chagas_dev_ref_materials/en/

7. Frasch AC, Cazzulo JJ, Aslund L, Pettersson U. Comparison of genes encoding Trypanosoma cruzi antigens. Parasitol Today 1991; 7: 148-151.

8. Houghton RL, Benson DR, Reynolds LD, McNeill PD, Sleath PR, Lodes MJ, Skeiky YA, Leiby DA, Badaro R, Reed SG. A multi-epitope synthetic peptide and recombinant protein for the detection of antibodies to Trypanosoma cruzi in radioimmunoprecipitationconfirmed and consensus-positive sera. J Infect Dis 1999; 179: 1226-1234.

9. Gomez Barroso JA, Aguilar CF. Chagas disease: a homology model for the three-dimensional structure of the Trypanosoma cruzi ribosomal P0 antigenic protein. Eur Biophys J 2014; 43: 361-366.

10. Bocharov EV, Sobol AG, Pavlov KV, Korzhnev DM, Jaravine VA, Gudkov AT, Arseniev AS. From structure and dynamics of protein L7/L12 to molecular switching in ribosome. J Biol Chem 2004; 279: 17697-17706. 
